Cayce MYERS*

\title{
Digital Immortality vs. "The Right to be Forgotten": A Comparison of U.S. and E.U. Laws Concerning Social Media Privacy
}

\begin{abstract}
This paper examines the contrast between United States and European Union laws concerning social media users' right to remove their online presence permanently. Currently, the United States and European Union represent two distinct approaches to the right of individuals to permanently remove personal content from social media. U.S. law favors social media companies keeping profile content within the digital sphere even when that person no longer wants it there. The European Union's approach social media privacy gives users more rights to remove themselves entirely from social media permanently (General Data Protection Regulation, Article 17, 2012). Using Myres McDougal's (1959) legal theory of international laws' effect on national policy, this legal study examines the social media privacy laws of the United States and European Union concerning user control of personal content. From this analysis, future implications of this international conflict, specifically the legal delineation of public and private spheres in the $21^{\text {st }}$ Century, are suggested.
\end{abstract}

Keywords: European Union, Privacy, Social Media, Media Law, International Law

\section{Introduction}

Unlike previous eras in which a person's past was relegated to a few photographs, a diary, or fading memories of those left behind, today the digital sphere provides a type of immortality within the Internet. Nowhere is this digital longevity more prevalent than in social media. The creation of social media sites in the early 2000s allowed users to create their own representation of themselves online complete with pseudo-diary entries, photos, and even detailed lists of personality traits. This online-self allowed Internet providers to compile large, detailed profiles of many users, creating a rich trove of data information. These data have become a commodity and are sold to service providers, corporate marketers, and online retailers who use this information as a core part of their business model. Data is even disseminated for free by other users, most notably users of social media outlets such as Facebook who "share" information or Twitter users who "retweet" posts. This new data reality creates a new environment in which massive amounts of personal information is cycled and recycled by users and companies.

Personal information stays within the Internet in perpetuity. Even those who have reached physical mortality can live-on in the digital sphere. Because of this, no one, living or dead, can outrun their past online. News stories, social media accounts, e-mails, and online purchases

* Department of Communication, Virginia Tech, US, mcmyers@vt.edu. 
continue to exist within the digital sphere. This makes it difficult for individuals to out-run or out-live their past deeds and actions. Rather, this information remains a permanent digital fixture. However, most individuals, at least within the American context, seem to accept this reality as a cost of living online. After all, many Americans may dismiss any concerns over digital privacy by arguing that their lives are mundane and not noteworthy. Aside from the fear of have their identity stolen (creating monetary concerns) many Americans' attitudes toward digital privacy is epitomized with the retort "who would care about what I do?"

Part of the reason for this attitude may be found in American law. Even though American legal scholars Samuel Warren and Louis Brandeis (1890) introduced the idea of legally protected privacy in their famous Harvard Law Review article "The Right to Privacy," American law privileges the ability to disseminate information. Part of the reason for this is the core protections of the First Amendment of the United States Constitution that protects the freedom of speech and the press. The ability to say what one wants about whatever one chooses is a fundamental concept within American constitutional law. With a few exceptions (e.g. fighting words, libel, slander, and obscenity), American jurisprudence protects speech regardless of the information. In fact, only in 1960 did famed torts scholar William Prosser fleshout causes of action, or the ability to bring a lawsuit, for invasions of privacy; even then it took state courts decades to codify these concepts.

European concepts of privacy differ than those in the United States. European laws privilege the rights of individuals to control the dissemination of information about them. Beginning in the 1970s in Germany, and later in Austria, Sweden, France and Spain, European countries passed statutes that gave individuals the right to protect and demand removal of data about themselves online (Schwartz, 2013). Commonly referred to as the right to be forgotten or le droit á l'oubli, French for the "right of oblivion," these laws allow individuals to control their data dissemination online to the point that search engines can theoretically be required to remove all information of individuals in search engine results (Rosen, 2012, p. 88). This creates a logistical and costly requirement for some search engines and websites because it requires them remove not only information that a user placed online, but also information that is re-used and disseminated, such as re-tweets, Facebook sharing, and data sales.

Within the European Union the "right of oblivion" is law for all member states. Beginning in 2012, the European Union began considering the General Data Protection Regulation [GDPR], which, among other things, codifies the right to be forgotten and enforces stringent enforcement of these protections outside the European Union This creates a privacy nightmare for search engines and social media sites which are mainly headquartered and subject to U.S. law. The GDPR represents a conflict of laws and philosophies between the United States and European Union, which have a workable, yet delicate, relationship concerning data sharing online.

This study explores this concept of privacy within E.U. and U.S. laws, specifically the European right to be forgotten. The study begins with the theoretical implications of conflicts between international and national laws and the current legal hegemony of E.U. privacy laws. Particular attention is paid to the current legal framework of E.U. privacy protection codified in the Directive 95/46/EC [Privacy Directive] and the newly recognized right to be forgotten. To illustrate the contrast between the European Union and United States, an overview of American privacy law is provided with analysis of how American law views removing private information. Finally, the May 2014 opinion by the Court of Justice of the European Union in Google Spain v. Agencia Española de Protección de Datos, a case examining the 
right to be forgotten in context with an search engine, is explored. Implications of this decision for E.U. and U.S. data sharing, and development of E.U. data protection regulations are discussed (Google Spain v. AEPD, 2013; Google Spain v. AEPD, 2014; Article 29 Data Protection Working Party, 2014).

\section{European Union Hegemony: Conflict Between International and National Laws}

Data sharing is an example of the tension between cultural and national values within an international legal context. The right to be forgotten illustrates a tension in the concept of the contours of public and private space within the realm of social media, international transactions, and the new digital age. International legal scholar Myres McDougal's approach to international law has been described as "an approach that devotes itself so centrally to the use of law as an instrument for the realization of the values of human dignity" (Falk, 1965, p. 67). In fact, this idea of "human dignity" is at play within the debate over data dissemination and individualized privacy. Writing in the late 1950s, McDougal (1959) argued that international laws had a particularly large impact on creating "values" such as "human dignity" (McDougal, 1959, p. 26; Falk, 1965, p. 67). McDougal (1959) wrote:

One may observe... both that these effective decisions as a whole are affected by certain perspectives of authority or lawfulness, projected by various aspiring systems of world public order, which purport to allocate competence for decision between the general community of states and particular states, and that these perspectives of authority about appropriate allocation of competence, because of their impact upon decision, also importantly affect the whole world social process, including the production and distribution of values by and for all peoples (p. 26).

This assessment of the impact of international law within a global context can be seen in E.U. lawmaking generally. Bradford (2012) argues that the most important aspect of E.U. laws is their application and imitation by non-E.U. nation-states. This so-called "Brussels effect" is created because of the large international economic dominance of the European Union. (Bradford, 2012, p. 3). If non-E.U. countries wish to engage in an economic partnership with E.U. members or the European Union itself, it is almost a de facto requirement that these non-E.U. nations craft regulatory guidelines that mirror E.U. laws. This is done in part because of the extraterritoriality of E.U. regulations which oftentimes reach beyond the European Union and call for international adherence to E.U. regulatory schemes (Schwartz, 2013).

The European Union's hegemony in regulatory policy is a fear anticipated by McDougal's (1959) theory on international laws. According the McDougal (1959), individual nation states frequently resist international laws and agreements because they erode individual national autonomy. McDougal (1959) argues nations have "a double interest in such inclusive competence" which means nations wish to have a voice within the development of international laws and nations have a need to create and maintain laws that affect local issues (p. 26). This legal dichotomy between international and national legal developments is viewed in terms of "authority and control" which permits a privileging of some legal entities (McDougal, 1959, p. 87). E.U. regulation presents a particularly perverse form of control within the international context. McDougal's (1959) concern was for international laws crafted by na- 
tion-states within an international organizational context, such as the European Union. However, as Bradford (2012) and Schwartz (2013) state, the European Union's legal impact does not stem from dialog with non-E.U. members in an international organization.

The European Union's impact on international legal development is found in multiple areas of regulation including privacy, product safety, trade regulation, and food quality (Bradford, 2012). Privacy laws, in particular, have been affected by the European Union with many countries (excluding the United States) within the Organization for Economic Cooperation and Development (OECD) adopting privacy laws similar to those found in the European Union. These privacy laws are extremely strict on the dissemination of privacy within the Internet and are counter to U.S. conceptualizations of privacy (Bradford, 2012). Nevertheless, many U.S. Internet companies that operate in a global marketplace must de facto adhere to these European Union privacy regulations to conduct business within Europe while other countries explicitly model their laws after E.U. directives. Part of the power of E.U. laws concerning privacy is that currently the European Union Privacy Directive forbids the sharing or dissemination of data to third party states unless those states comply with E.U. privacy laws. While the Privacy Directive provides some exceptions for third party states who do not have laws similar to that of the European Union, notably the United States, many nations opt to comply with E.U. privacy regulations to engage in trade and digital data sharing.

Bradford (2012) points out that many within the United States do not see Europe as having considerable power within the $21^{\text {st }}$ Century. However, looking at global commerce and the fact that the GDP of the European Union is higher than that of the United States according to the International Monetary Fund, the European Union is a formidable power within an economic context. Because the legal traditions of the United States do not embrace those values of privacy held by the European Union and that digital commerce is driven by U.S. corporations there is a high likelihood that U.S. and E.U. privacy policies will create a potential conflict in the digital marketplace. These conflicting values of privacy represent a powerful dichotomy over the power of keeping, storing, and dissemination of information (Schwartz, 2013).

\section{European Union Laws Concerning Data Protection}

E.U. laws frequently take the form of requiring third-party nations to comply with E.U. regulations. Even within the structure of the European Union, member states must also codify these E.U. laws within their own national legislation. Within the structure of E.U. lawmaking it is important to note the European Union operates by issuing directives and regulations. Directives are pieces of legislation that require E.U. member states to pass national legislation that is in sync with the European Union directive. Regulations, however, are much more powerful than directives. E.U. Regulations are laws that are more directly binding on member-states and do not require for nations to pass legislation that directly reflects the regulations' requirements. Once a regulation is passed it is automatically law over the European Union's member states. Currently the issue within the European Union's privacy law is the creation of a new regulation that creates more power for the European Union directly in enforcement and potentially overrides the Privacy Directive that has governed E.U.-U.S. privacy interactions since 1995 . 


\section{a. E.U. Directive on Privacy and Personal Data}

The European Union's current laws on privacy and data processing are governed by Directive 95/46/EC commonly referred to as the Privacy Directive. The Privacy Directive protects individual privacy rights far more than current U.S. laws. The Privacy Directive Article 26 expressly forbids the dissemination of E.U. citizens' private information to third-party non-E.U. countries whose own privacy laws provide less protection than those of the European Union. The United States certainly falls into this category and has been viewed as providing less privacy protection than allowed by the European Union since the inception of the Privacy Directive in 1995. Because the United States and European Union have a close economic relationship, particularly in terms of data protection, rules developed that permit data sharing between E.U. and U.S. companies.

Schwartz (2012) argues that when the Privacy Directive was first introduced in 1995, many E.U. member-states already had national laws that reflected many of its provisions concerning privacy. He argues that within the Privacy Directive there is a type of dual purpose that balances the needs of data sharing and individual privacy. While other laws, notably those in the United States, tend to favor one value over the other (with the United States favoring data sharing) the European Union attempts to balance the two interests for optimal effect (Schwartz, 2013). Essentially the data protection provided in the Privacy Directive disallows the ability to disseminate data that is "revealing racial or ethnic origin, political opinions, religious or philosophical beliefs, trade-union membership, and the processing of data concerning health or sex life" (Directive 95/46/EC, Article 8 1). Moreover, in Article 14 of the Privacy Directive individual E.U. citizens are allowed to prevent the dissemination of their private information in cases where the controller (e.g. search engines) of the data is using the information for their own purposes or for direct marketing (Directive 95/46/EC, Article 14(a)(b)). Within these regulations there are exceptions to the blanket ban on information described in Article 8 - 1 . Moreover the power of the individual to control the removal of their data is restricted to certain circumstances under Article 14(a) and (b). However, the privacy limitations of this Directive are more restrictive than those privacy laws found in the United States.

The Privacy Directive Article 25 directly deals with disseminating data to non-E.U. countries that do not provide the level of privacy protection articulated in the Privacy Directive. Article 25 ๆ 1 states:

The Member States shall provide that the transfer to a third country of personal data which are undergoing processing or are intended for processing after transfer may take place only if, without prejudice to compliance with the national provisions adopted pursuant to the other provisions of this Directive, the third country in question ensures an adequate level of protection (Directive 95/46/EC, Article 25 I| 1).

Under this provision of the Privacy Directive, data dissemination is banned between E.U. companies and those in the United States. However, the Privacy Directive provides three caveats that allows for data dissemination between E.U. and U.S. companies. Privacy Directive Article 26 allows for data sharing in certain situations where the non-E.U. country complies with certain regulations in a narrow sense. There are three such exceptions in which U.S. corporations use to facilitate U.S.-E.U. data sharing: U.S.-E.U. Safe Harbor Agreement agreed to in 2000, contractual clauses exception in Article 26 2, and corporate rules found in E.U.'s Article 29 of the Data Protection Working Party. These exceptions allow for limited corporate protection of E.U. data sharing without incorporating these E.U. privacy laws 
into U.S. law. Each exception provides for safeguards for E.U. data while allowing U.S. corporations to operate under the auspice of U.S. law (Schwartz, 2013).

The United States-European Union Safe Harbor Agreement began in 2000 and permits for certain transfers of data between the European Union and United States if the United Statesbased companies comply with certain agreed upon standards that incorporate E.U. privacy protections. Specifically, the Safe Harbor Agreement requires that organizations obtaining data from the European Union use that information only within the context of the "purposes for which it has been collected" (Safe Harbor Framework, 2013, p. 13). The Safe Harbor Agreement severely restricts the dissemination or selling of personal information to other organizations. Companies or organizations wishing to operate under this Safe Harbor Agreement must apply to become certified as part of Safe Harbor. This certification requires those U.S. companies to subject themselves to privacy relations not found in U.S. law and to permit themselves to be regulated by federal agencies (Safe Harbor Framework, 2013). This agreement is regulated by the United States government, notably the Federal Trade Commission (FTC), and requires the United States bring suit against U.S. corporations that violate E.U. privacy requirements articulated in the Safe Harbor Agreement (2000).

U.S. federal enforcement of the Safe Harbor Agreement must occur for there to be good faith between the United States and European Union. Google and Facebook were cited by the Federal Trade Commission for violating Safe Harbor Agreement privacy standards (In the Matter of Google Inc., 2011; In the Matter of Facebook Inc., 2012). In Google Inc. (2011), the Federal Trade Commission cited Google for sharing users' information within their new social media platform Google Buzz. Even if Google e-mail users decided to opt out of Google Buzz, their information was still provided and disseminated within Google Buzz causing a violation of the Safe Harbor Agreement. Similarly Facebook Inc. (2012) involved a violation of the Safe Harbor Agreement when Facebook introduced certain gaming platforms that disclosed personal information about account holder to facilitate joining the gaming platforms. Both of these disseminations of private information illustrate how E.U. privacy regulations can adversely affect social media sites' business models.

Because the Safe Harbor Agreement requires organizational certification and federal oversight, many U.S. organizations opt for the other two exceptions that allow for E.U. data sharing. The first of these is found in the Privacy Directive Article 26 - 2 which allows for "contractual clauses" between E.U. and U.S. organizations to provide particular data privacy protections that adhere to E.U. standards. These contractual clauses must provide recourse for those individuals whose data is misused. This assignment of liability falls to both E.U. and U.S. parties and frequently requires each party to be responsible for all of the damages caused by a privacy breach (Schwartz, 2013).

The third exception to Article 25 is what Schwartz (2013) calls "Binding Corporate Rules" (p. 1983). This is basically an agreement accepted by the European Union Article 29 Working Party that states single organizations can have internal rules that protect data when that data is shared internally within an organization. Unlike the Safe Harbor Agreement or the Article 26 I 2 protections, this rule applies only to multi-national corporations who use data from E.U. citizens within their organization's internal operations. For a company to be allowed to use this exception they must apply for permission with the European Union's Working Party.

These exceptions to Article 25 of the Privacy Directive proved valuable in facilitating data sharing between the United States and European Union. It permits the European Union to heighten privacy laws while allowing the United States to retain its traditional concepts of 
privacy. Bradford's (2012) "Brussels effect" has only slightly affected U.S. corporations, which allows them to operate most of the time in an American legal context that is pro-dissemination. However, in 2012 this complex balance between E.U. and U.S. privacy laws and data sharing was challenged by General Data Protection Regulation (GDPR). This regulation would radically depart from the more nuanced standards of the Privacy Directive and prove a challenge to future U.S. and E.U. data sharing relationships.

\section{b. Regulation for General Data Protection Regulation}

In January 2012, the European Union proposed a new approach to data protection. This regulation, known as GDPR, departs from some of the more pro-dissemination articles of the Privacy Directive (1995). This regulation included a more powerful role for E.U. administration and included more controversial, pro-privacy protections for E.U. citizens. Perhaps the most controversial provision in the GDPR is the right to be forgotten, which would allow individual users to demand removal of their information by websites, search engines, and other online users. In announcing the new GDPR, Viviane Reding, the Vice President of the European Commission, said "people must be able to easily take their data to another provider or have it deleted if they no longer want it to be used...I want to explicitly clarify that people shall have the right - and not only the 'possibility' - to withdraw their consent to the processing of the personal data they have given out themselves" (Reding, 2012, p. 5). Because of this impending legal sea-change, data sharing between E.U. and U.S. corporations could be permanently changed.

\section{i. Impact on Current Structure of EU Privacy Laws}

Part of the reason this new approach to privacy and data sharing was introduced was the changes that occurred between the Privacy Directive, first adopted in 1995, and the rise of social media in the 2000s. The European Union felt that a more structured and restrictive policy for privacy needed to be implemented to stem the tide of dissemination of private information. Within the GDPR there is an increased role for the European Union in that the European Data Protection Board, rather than individual member states, will regulate data privacy laws. Within the GDPR the European Commission, the executive branch of the European Union, has final authority to give continual guidance to the implementation of the GDPR. This centralized authority of the European Union takes away many of the informal practices of the Privacy Directive. It allows for the European Commission to play a large role in the continual evolution of the GDPR, and eliminates certain exceptions that the Privacy Directive currently allows for non-member nations.

GDPR Article 9 disallows the use of information that reveals a person's race, ethnicity, political views, religion, union membership, health, and sexual practices unless it falls into certain exceptions such as legal defense, consent of the individual, or certain public interests. Compounding this restriction is that organizations processing the data may be held liable privacy violations even if there is consent by the individual if it is decided that there is an imbalance between data processing and individual privacy rights.

Controllers, those organizations in possession of the data, have the burden of proof to show they did obtain consent if an individual brings a lawsuit (GDPR, Article 1 『1). Controllers must also make themselves known to individual users and must provide contact in- 
formation to users (Article 14, \1). When data is collected, users must be notified by controllers if the data was transferred without the users' knowledge (Article 14, 13 ). Users can also contact the controllers of this data at any time to inquire if their information is being processed by the controller and for what purposes the data is being processed (Article 15, $\uparrow$ 1). If any information is determined to be inaccurate by the user, the controller can be forced by the user to remove the information immediately from the Internet (Article 16). Controllers are also under the obligation to prove their processing of data is consistent with certain narrow objectives of the organization. This eliminates certain analytical processing of large groups of data to create demographic profiles (Article 19, 1). Even within an organization, the internal policies must reflect the privacy rules dictated in the GDPR or risk sanction if these policies are not put into place (Articles 22-24). The new penalties outlined in the GDPR for violating these laws are severe. Companies can be subject to 1 million fines or up to 2 percent of "worldwide turnover," commonly referred to in the United States as gross sales, for a fiscal year (GDPR, Article 79, \6).

\section{ii. Droit á L'Oubli: The Right to be Forgotten}

The most controversial and perhaps most threatening to search engines is the GDPR's Article 17 which codifies the right to be forgotten. Commonly referred to in French as droit á l'oubli, the right to be forgotten has a long and complex history within European law (Mantelero, 2013). Originally droit á l'oubli began as a concept for former criminals who had served their sentences in prison and were set free. The idea was that since they have paid their proverbial debt to society, they were entitled to a fresh started unencumbered by their criminal past. Because of this, their past criminal histories were "obliterated," and they began their lives anew as productive members of society. American law, by contrast, has no such historical justification for removing a person's past, criminal or otherwise. American law has always favored the idea that free speech allowed for a person's criminal past to become part of public record because of the need to protect society. It is this clash of legal and philosophical values that underpins the right to be forgotten issue.

Article 17 1 1 of the GDPR states that a user has a "right to obtain from the controller the erasure of personal data relating to them and the abstention from further dissemination of such data, especially in relation to personal data" when there is no use for the data or, more importantly, when the "data subject" decides he or she no longer wants the information public. Moreover, under Article 17 \ 2 the controller not only has to remove data on sites they are in control of but must also "take all reasonable steps, including technical measures...to inform third parties which are processing such data, that a data subject requests them to erase any links to, or copy or replication of that personal data."

This third party can be another search engine or web company, but it also includes other individual users, such as Facebook friends or Twitter followers. Under this regulation, retweets, sharing, comments, re-posting, or posted comments constitute dissemination of personal information. Search engines and social media outlets are required to not only inform these users of this request, but also take technical measures to remove these specific data requests about specific pieces of data. These data requests can be quite particular. Requests could include the removal of a picture, post, comment, or tag that the data subject no longer wants disseminated on the Internet. Controllers are not only required to remove information when requested, but they are also required to limit access to data when the information is no 
longer used by the controller or if there is some question as to whether the data is a truthful representation of the data subject (Article 17, $\mid 4$ ).

There are exceptions to this rule for required removal. The GDPR Article 17 ? 3 allows for controllers not to remove data when it involves free express or when "public interest" such as issues of health, scientific research, legal requirements, or historical significant preservation arise that requires the maintenance of data. However, these exceptions are extremely limited and subject to the review of the European Commission and European Data Protection Board. Scholars point out that required removal or limited access to data provides a logistical problem for many search enginess. It first requires non-E.U. based companies to adhere to E.U. regulation in their maintenance and promotion of world-wide websites and search engines. Second, and perhaps most problematic, is that these regulations direct companies to respond immediately to the requests of individual users who at any given time may have small, complex removal requests that are difficult to track and expensive to remove.

In March 2014 the right to be forgotten in Article 17 was replaced with a more moderate right to erasure. The major difference between the right to be forgotten and right to erasure is unclear because both deal with the removal of personal information from controllers of data, such as search engines. It was against this backdrop that the Court of Justice issued its decision on the right to be forgotten in May 2014.

\section{Google Spain v. Agencia Española de Protección de Datos: Reconsidering the Right to be Forgotten}

These debates over E.U. privacy and the right to be forgotten reached an apex in May 2014 when the Court of Justice issued an opinion declaring the European Union recognized the right to be forgotten. In November 2014 European Union officials argued the right to be forgotten should extend worldwide (Scott, 2014). The application of this new law is still in its infancy. However, by recognizing the right to be forgotten the European Union has permanently changed the way E.U. citizens and businesses view online image management.

The right to be forgotten case began in Spain in 1998 when Mario Gonzáles had a newspaper article written about a state auction to raise money for back taxes he owed for Spanish social security. These articles ran twice and later were placed in an online edition of the newspaper. In 2009, Gonzáles discovered through a Google search of his name that these articles were still online. Wanting them removed, he contacted the newspaper directly asking them to remove the articles. The newspaper declined. Gonzáles then contacted Google Spain asking them to remove the links to the articles, but Google Spain also declined. Afterward, Gonzáles filed a complaint with Agencia Española de Protección de Datos [AEPD] arguing that he had a right to have the articles removed online. AEPD agreed and ordered Google Spain to remove the articles from their search results. This AEPD decision was appealed to the Audiencia Nacional, Spain's highest appeals court, which referred the case to the Court of Justice. In this case several issues were decided, such as the power of the Court to hear a case from a foreign corporation such as Google. However, the most important aspect of this decision was whether a company like Google can be held responsible as a controller of data and whether the Privacy Directive allows for a right to be forgotten.

Before the Court of Justice ruled on the right to be forgotten, the Advocate General of the Court of Justice argued there was no right to be forgotten within E.U. law. In a nonbinding rec- 
ommendation to the Court of Justice the Advocate General argued that that a search engine such as Google is not a controller of data for purposes of the Privacy Directive. He also argued that the GDPR Article 17, which codifies the right to be forgotten, does not seem to consider search engines as controllers, but rather third parties. The Advocate General argued:

In contemporary information society, the right to search information published on the internet by means of search engines is one of the most important ways to exercise that fundamental right. This right undoubtedly covers the right to seek information relating to other individuals that is, in principle protected by the right to private life such as information on the internet relating to an individual's activities as a businessman or politician. An internet user's right to information would be compromised if his search for information concerning an individual did not general search results proving a truthful reflection of the relevant web pages but a "bowdlerized" version thereof (Google Spain v. AEPD, 2013, p. 23).

Despite the Advocate General's influence on the Court of Justice, the court disagreed with the Advocate General in a decision in May 2014. The Court of Justice held that the right to be forgotten did exist in E.U. law. The court held that search engines were controllers of digital information as defined by Article 2 of Directive 95/45/EC and that search engines stored this information within their websites. Because of this the Court of Justice held that search engines had a responsibility to remove certain pieces of information from the web when requested. The court also held that even though search engines like Google headquartered in the United States they are subject to E.U. privacy laws because they operate in E.U. member states. The court ruling directed search engines to remove information from their search engine results when requested by individual users (Google Spain v. AEPD, 2014).

This ruling created a large amount of uncertainty among users and search engines. After May 2014 search engines were inundated with requests from users demanding the removal of personal information online. This prompted the Data Protection Working Party to issue a guideline detailing the contours of the right to be forgotten law. The guideline states that information that is removed is only removed from search engine results associated with individuals' names. Incidental links to source information that are generated from other search terms are not permanently removed (Article 29 Data Protection Working Party, 2014).

Even though users can contact individual website to request removal of content, right to be forgotten removal requests only affects search engines. The guideline states that once an E.U. resident or citizen requests removal of information the search engine can evaluate the claim. Individual websites do not have contact the individual websites where the original content is located to notify them certain information is being removed from search engine results. Perhaps most importantly for international communication the search engines removing information are limited to those in the European Union. United States search engine results remain the same regardless if there is a E.U. request for removal of content.

The most complex part of removal requests is determining what constitutes a valid request for removal. The new guidelines released in November of 2014 hope to remedy the confusion caused by the new law. The guideline states that the right to be forgotten does not give users a carte blanche to demand information be removed. Information that is perceived to be important to the general public's knowledge will not be removed regardless of users' requests to remove. When a search engine denies a request for information removal, the search engine must provide a reason for the denial. Users can appeal this decision to the European Data Protection Authorities. The guidelines give thirteen common criteria to evaluate a removal request. These criteria look to: 
1) Whether the information is listed when a person's name is searched;

2) What is the status of the user in "public life;"

3) The age of the person requesting the material;

4) The truthfulness of the information about the person;

5) How much information exists online about the person;

6) Whether the information about the person is "sensitive" or "private" information;

7) Is the information about the person current;

8) Is the information about the person "causing prejudice"

9) Does the information place the person "at risk;"

10) Was the information purposefully placed online or was the information something a person would expect to remain private?;

11) Was the information placed online because of a journalist or news outlet;

12) Was the information placed online because it was legally required to be made public;

13) Is the information online regarding criminal behavior or crimes. (Article 29 Data Protection Working Party, 2014, pp. 13-20).

While these guidelines do not provide dispositive answers to what can be removed online, they do give a general sense of what the Court of Justice intended when they found a right to be forgotten law exists. More newsworthy information, such as a major criminal conviction, and information one would expect to find online, such as a professional affiliation, would likely remain online even if a user requested that information be removed. Likewise, information about a minor, personal information about health issues, or defamatory statements about an individual would likely be the type of information that would be removed if requested. These guidelines illustrate the European Union's attempt at striking a balance between newsworthy information with public interest and private information that is personal. The European Union's guidelines are a first attempt at clarifying the Court of Justice's May 2014 decision. Only time will tell how this new law will be implemented in the digital sphere (Article 29 Data Protection Working Party, 2014).

\section{The Right to be Forgotten in the United States}

Unlike the European legal system the United States has always valued the ability to disclose information over the ability to conceal it. Part of the reason for this is the value placed in the United States on freedom of speech and press and the underlying idea that a marketplace of ideas is necessary for the preservation of democracy. Within First Amendment U.S. Supreme Court jurisprudence, the fear that a regulation may restrict free speech to the point that people or organization may suppress their ideas is dominant. This fear, referred to as a "chilling effect," is a major reason why many regulations on speech in the United States are struck down (Lamont v. Postmaster General, 1965; Wieman v. Updegraff, 1952). However, privacy rights emerged in American legal scholarship as early as 1890 when Warren and Brandeis argued that privacy rights developed as a byproduct of legal evolution. They equated the injury done to those in traditional tort law (i.e. battery, assault) to be replicated by invasions of privacy. Because of this, Warren and Brandeis (1890) argued that there existed separate causes of action in tort for invasions of privacy. These invasions could result in damages for the person whose privacy rights were violated. Commenting that a person's privacy is a form of personal property Warren and Brandeis (1890) wrote: 
The common law has always recognized a man's house as his castle, impregnable, often even to its own officers engaged in the execution of its commands. Shall the courts thus close the front entrance to constituted authority, and open wide the back door to idle or prurient curiosity? (p. 220).

In 1890, Warren and Brandeis' ideas on privacy were revolutionary in American jurisprudence. They argued certain personal information could not be disseminated without prior approval of the subject. What made these new ideas about privacy unique was their concept of privacy protected truthful information about a person. Libel and slander had been a cause of action in English common law, even cause for criminal punishment. However, dissemination of truthful information had no traditional cause of action in American or English law.

As mentioned in the introduction, Warren and Brandeis' (1890) concept of privacy laws were not codified in the United States until the 1960s. William Prosser, a noted torts professor, wrote an influential law review article in which he separated the various causes of action for privacy torts. These causes of action were: intrusion upon seclusion (or invading one's private space); public disclosure of private facts; false light (or the telling of information about a person which could create positive or negative misperceptions about them); and appropriation (using one's likeness or name without permission). These individual causes of action were later incorporated into Prosser's Restatement of Torts which gained popularity throughout U.S. legislatures.

What this history shows is that the ability to remove information or have a right to be forgotten is not present within American law. All of Prosser's (1960) privacy torts involve a use of an individual's privacy without their consent. All the remedies for these privacy violations are monetary and there is no argument that the information can simply be removed from society. As McNealy (2012) points out, these civil causes of action come closest to providing an American version of the right to be forgotten. However, she notes that this American notion of privacy differs from that found in E.U. law because it does not provide the erasure remedy and it only affects individuals who have not consented to the dissemination of their private information

McNealy (2012) adds that American jurisprudence seems to favor disclosure of personal information when it has a level of newsworthiness. The United States Supreme Court held in Cox Broadcasting v. Cohn (1975) that the State of Georgia could not take punitive measures against a newspaper for publishing the name of a rape victim because the name was newsworthy. Other U.S. Supreme Court decisions have extended this rationale of newsworthiness as a reason to publish certain information (Nebraska Press Association v. Stuart, 1976; Landmark Communications Inc. v. Communications of Virginia, 1978). Later, the United States Supreme Court held that if the press lawfully finds out information they may print it even though there may be state prohibitions of disseminating potentially sensitive information, such as the name of a rape victim or the name of a juvenile charged with murder (Florida Star v. B.F.J., 1989; Smith v. Daily Mail Publishing, 1979).

Federal regulations have emerged to protect data dissemination for online content. Currently there is an attempt in Congress to pass legislation to prevent online tracking of individuals (Do Not Track Me Online Act, 2011). States have also attempted to pass legislation that prevents online tracking of individuals, such as the California Senate Bill 761 introduced by Alan Lowenthal that requires corporations to disclose their privacy protection breaches and provide transparency in corporations' use of online data.

However, in 2014 there are no American laws, federal or state, that specifically deal with data regulation in a manner similar to the European Union's GDPR. From examining the his- 
tory of privacy in the United States and the views of privacy law development, it is clear that American jurisprudence has an inherent skepticism of secrecy. Part of this is born out of traditions of speech and press that are codified in the United States Constitution. Another part of this is that privacy protection is viewed as something that needs to be regulated only when something goes awry. In the European Union, privacy is viewed more personally and abstractly. An individual's right to their own private information or control over their image is something that is a form of property that cannot be eroded.

\section{Implications on European Union-United States Privacy Laws and Social Media Growth}

This study illustrates the cultural and philosophical tensions with the increased role of globalized media, specifically the Internet. Social media and the sophistication of search engines have created challenges for cultural norms regarding privacy. Even though the worldwide-web created a more interconnected global dialog, it has highlighted the cultural differences between privacy, access, and control. The European Union-United States differences on privacy serve as just one example of the types of difficulties that stem from these new laws. Looking at this struggle over the right to privacy and the right to be forgotten, there is an obvious tension between individual and corporation, private verses public, and U.S. verses Europe.

Rosen (2012) argues that the right to be forgotten is appealing in the abstract, but when taken in context with the larger implications of search engine and website maintenance, threatens the interconnectivity of the digital age. He argues that at the most basic level the ability to remove information a person places about oneself is generally accepted by both U.S. and E.U. laws. However, once the request goes beyond this simple removal, the tasks become more complex and potentially damaging to the maintenance of a world wide web. If a person wants to remove something someone else re-posted or disseminated, such as a re-tweet, about them, the European Union model would permit such as request. Even more problematic for Rosen (2012) is the idea that under the GDPR a person could require another person or media outlet to take own original content, such as a news story. This creates a serious threat to First Amendment issues of free speech and freedom of the press that creates a chilling effect on free speech and expression.

Schwartz (2013) views these new E.U. regulations more optimistically, but does argue they have the potential to breakdown the relationship between the United States and European Union. He argues placing power in the executive levels of the European Union threatens the goal of local member-state power. These regulations also create an environment in which American laws could be threatened by Bradford's (2012) "Brussels effect" which imposes a European philosophical values on non-European countries, thus eroding sovereignty and national identity which are key for the maintenance of nation-states' values (Bradford, 2012, p. 3; McDougal, 1959).

Regardless of one's academic stance on the right to be forgotten it is evident that the European Union's new approach to digital privacy will change the Internet. As the right to be forgotten becomes more developed in the European Union and is applied to non-E.U. nations, the United States will likely face an international challenge to its traditional legal approach to privacy. This tension is only in the beginning. As technology develops in unique 
ways the international dimensions of privacy and Internet regulation will be a continual discussion of legal scholarship both the in the European Union and United States.

\section{References}

Article 29 Data Protection Working Party. (2014). Guidelines on the Implemntation of the Court of Justice of the European Union Judgment on "Google Spain and Inc. v. Agencia Española de Protectión de Datos (AEPD and Mario Costeja González" C-131/12. Retrieved from November 28, 2014 http://ec.europa.eu /justice/data-protection/article-29/documentation/opinion-recommendation/files/2014/wp225_en.pdf.

Bradford, A. (2012). The Brussels Effect, Northwestern University Law Review, 107, 1-68. Cox Broadcasting v. Cohn, 420 U.S. 469 (1975).

California Senate Bill 761 (2011). Do Not Track Me Online Act, H.R. 654 (112 ${ }^{\text {th }}$ Congress, 2011-2013).

European Union, (1995). Directive 95/46/EC of the European parliament and of the council of 24 October 1995 on the protection of individuals with regard to the processing of personal data and on the free movement of such data. Retrieved from website: http://ec.europa.eu/justice/policies/privacy/docs/95-46ce/dir1995-46_part1_en.pdf

European Commission, (2012). Regulation of the European parliament and of the council on the protection of individuals with regard to the processing of personal data and on the free movement of such data (general data protection regulation). Retrieved from website: http://ec.europa.eu/justice/data-protection /document/review2012/com_2012_11_en.pdf

Falk, R. (1965). International Legal Order: Alwyn V. Freeman vs. Myres McDougal, The American Journal of International Law, 59, 66-71.

Federal Trade Commission, (2009). US * EU safe harbor framework. Retrieved from website: http://trade.gov /publications/pdfs/safeharbor-selfcert2009.pdf

Mantelero, A. (2013). The eu proposal for a general data protection regulation and the roots of the 'right to be forgotten'. Computer Law \& Security Review, 29, 229-235.

Florida Star v. B.F.J., 491 U.S. 524 (1989). Google Spain v. Agencia Española de Protección de Datos, Case C-131/12 Opinion of Advocate General Jääskinen. June 2013.

Google Spain v. Agencia Española De Protección De Datos. European Court of Justice. May 2014.

In the Matter of Facebook Inc., FTC file No. 092-3184, Docket No. C-4365.

In the Matter of Google Inc., FTC file No. 102-3136, Docket No. C-4336.r

Lamont v. Postmaster General, 381 U.S. 301 (1965).

Landmark Communications v. Va, 435 U.S. 829 (1978).

McDougal, M. (1959). The Impact of International Law upon national Law: A Policy-Oriented Perspective. South Dakota Law Review, 25, 24-92.

McNealy, J. (2012). The Emerging Conflict Between Newsworthiness and the Right to be Forgotten. Northern Kentucky Law Review, 39, 119-135

Nebraska Press Assoc. v. Stuart, 427 U.S. 539 (1976).

Posner, R. (1960). Privacy. California Law Review, 48, 383-423.

Rosen, J. (2012). The Right to be Forgotten. Stanford Law Review, 64, 88-92.

Reding, V. (VP of European Commission) (2012, Jan 22). The EU data protection reform 2012: making Europe the standard setter for modern data protection rules in the digital age. [Speech].

Schwartz, P. (2013). The EU-U.S. Privacy Collision A Turn to Institutions and Procedures, Harvard Law Review 126, 1966-2009.

Scott, M. (2014, November 16). 'Right to be Forgotten' Should Apply Worldwide, E.U. Panel Says. New York Times. Retrieved November 28, 2014, from http://www.nytimes.com/2014/11/27/technology/right-tobe-forgotten-should-be-extended-beyond-europe-eu-panel-says.html?_r=0

Smith v. Daily Mail Publishing, 443 U.S. 97 (1979).

Warren, S. \& Brandeis, L. (1890). The Right to Privacy, Harvard Law Review, 5, 193-220.

Wieman v. Updegraff, 344 U.S. 183 (1952). 